\title{
Elimination of gatifloxacin from water: Treatment by electro-Fenton process and highlighting of a biological post-treatment
}

\author{
Mohamed Réda Arhoutane, ${ }^{1, *}$, Ghizlan Kaichouh², Muna Shueai Yahya ${ }^{3}$, Miloud El Karbane ${ }^{4}, H_{i n d}$ \\ Chakchak $^{5}$, Kacem El Kacemi ${ }^{1}$ \\ ${ }^{1}$ Laboratoire d’Électrochimie et Chimie Analytique (LECA), Faculté des Sciences de Rabat, Université \\ Mohammed V, Rabat, Maroc \\ ${ }^{2}$ Laboratoire des Matériaux, Nanotechnologies et Environnement, Département de Chimie, Faculté des Sciences, \\ Université Mohammed V, Rabat, Maroc \\ ${ }^{3}$ Department of Chemistry, Faculty of Education, Hodeidah University, Hodeida, Yemen \\ ${ }^{4}$ Laboratoire de Chimie Analytique et de Bromatologie, Faculté de Médecine et de Pharmacie, Université \\ Mohamed V, Rabat, Maroc \\ ${ }^{5}$ Centre National pour la Recherche Scientifique et Technique (CNRST-UATRS), Rabat, Maroc
}

\begin{abstract}
This study concerns the oxidative degradation and mineralization of gatifloxacin in aqueous solution at $\mathrm{pH}=3$, and the presence of $\mathrm{Fe}^{2+}$ as a catalyst using electro-Fenton (EF) process, with carbon felt as a cathode and platinum as an anode. The chemical oxygen demand evaluates the mineralization by assessing the applied current value and concentration of catalyst $\mathrm{Fe}^{2+}$. Some stable by-products of gatifloxacin have been identified using highperformance liquid chromatography and liquid chromatography tandem mass spectrometry (LC-MS/MS). The second part of this paper concerns the study of the biodegradability in determining $\mathrm{BOD}_{5} / \mathrm{COD}$ during the mineralization of gatifloxacin by EF in order to evaluate the possibility of coupling electro-Fenton process with the biological one. This leads to an efficient treatment of water contaminated by this antibiotic at a lower cost.
\end{abstract}

Keywords: treatment by electro-Fenton; gatifloxacin antibiotic; oxidative degradation; mineralization; biodegradation, essays in an aqueous medium.

\section{Introduction}

Given the fact that antibiotics are produced in order to cause pharmacological effects in organisms, it is not surprising that numerous studies have demonstrated that antibiotics have side effects on human health and the environment ${ }^{1}$. Also, the byproducts of these kinds of pharmaceutical substances are generally more toxic than the starting molecules during their oxidation in the ecosystem, thus causing a real danger on the environment. This situation has caused concern in public opinion about the hygienic and aesthetic quality of drinking water. Thus, scientists have had a challenge in order to eliminate antibiotics from water. They use some technics such as advanced oxidation processes (AOPs) including, ozonation 2, photocatalysis ${ }^{3,4}$, electro-Fenton, Photo-Fenton ${ }^{5-8}$, hybrid technique ${ }^{9}$ etc. Indeed, AOP's principle of operation articulates on an in situ generations of hydroxyl radicals ${ }^{\circ} \mathrm{OH}$. These molecules have an oxidizing power more than the other molecules usually employed like $\mathrm{H}_{2} \mathrm{O}_{2}, \mathrm{Cl}_{2}$,

*Corresponding author: Mohamed R. Arhoutane

Email address: med.reda.144@gmail.com

DOI: http://dx.doi.org/10.13171/mjc841906066mra
$\mathrm{ClO}_{2}{ }^{-}$or $\mathrm{O}_{3}$. So, these radicals arrive to mineralize the organic and organometallic substances totally or partially.

Among the pollutant antibiotics, there is gatifloxacin (destined to treat sensitive germ infections) where one study has clarified the aqueous photodegradation of this antibiotic, determining degradation kinetics and the formation of photoproducts ${ }^{10}$. Another study has shown that the photodegradation of gatifloxacin in freshwater and seawater is not as faster as in pure water, so, there are the integrative effects of $\mathrm{pH}$ and dissolved substances in the solution, such as humic acids, on photodegradation ${ }^{11}$.

In the same context and electrochemistry, the efficacy of "Electro-Fenton" (EF) process in the mineralization of drugs part of the family of persistent organic pollutants in water was demonstrated.

The EF process articulates on the in situ generations of ${ }^{\circ} \mathrm{OH}$ (reaction (1)) at $\mathrm{pH}=3^{12-14}$.

Received May 11, 2019

Accepted June 2, 2019

Published June 6, 2019 


$$
\begin{aligned}
& \mathrm{H}_{2} \mathrm{O}_{2}+\mathrm{Fe}^{2+}+\mathrm{H}^{+} \rightarrow \cdot \mathrm{OH}+\mathrm{Fe}^{3+}+\mathrm{H}_{2} \mathrm{O} \\
& \mathrm{O}_{2}+2 \mathrm{H}^{+}+2 \mathrm{e}^{-} \rightarrow \mathrm{H}_{2} \mathrm{O}_{2} \\
& \mathrm{Fe}^{2+}+1 \mathrm{e}^{-} \rightarrow \mathrm{Fe}^{3+}
\end{aligned}
$$

The reproduction of $\mathrm{Fe}^{3+}$ (reaction 3 ) from the reduction of $\mathrm{Fe}^{2+}$ produced by and the regeneration of $\mathrm{H}_{2} \mathrm{O}_{2}$ (reaction 2) ensure the generation of hydroxyl radicals ${ }^{\circ} \mathrm{OH}$ (reaction 2 ).

In acidic solution, the oxidizing power of ${ }^{\circ} \mathrm{OH}$ is very elevated (potential $=2.8 \mathrm{~V} / \mathrm{SHE}$ ), and with efficient reactivity. Thus, these radicals may degrade any organic molecule in an aqueous medium and leading in the end to the mineralization to $\mathrm{CO}_{2}$.

Overall, during mineralization of organic molecules by AOPs, the biorefractory molecules oxidize into small molecules biologically degradable. Thus, the coupling of AOPs with the biological process is strongly advised to eliminate efficiently and economically, the persistent organic pollutants from water ${ }^{15-20}$.

This paper clarifies the combination possibility of EF process and biological one for efficient elimination of gatifloxacin in aqueous solution. The electrochemical cell employed in this study contains a carbon-felt cathode and a platinum anode. Different experimental tests have been realized on the aqueous medium of gatifloxacin at constant applied current, at $\mathrm{pH}=3$ and using $\mathrm{Fe}^{2+}$ as a catalyst. The first study concerns the effect of the applied current and the concentration of $\mathrm{Fe}^{+}$(catalyst) on the degradation and mineralization of gatifloxacin. Then, different concentrations of gatifloxacin were prepared in order to study their degradation and mineralization by monitoring the chemical oxygen demand (COD). The identification of the interaction of high-performance liquid chromatography (HPLC) and liquid chromatography-mass spectrometry (LC-MS / MS). On the other hand, the monitoring of the biodegradability with electrolysis allowed the estimation of the optimal time to pass from the electro-Fenton process (EF) to the biological process. In order to carry out the biodegradation tests, the domestic wastewater was used, knowing that the value of $\mathrm{BOD}_{5} / \mathrm{COD}$ is the representative value of the biodegradability ${ }^{21}$. This report gives information on the part of the organic substances present in the solution that can be biodegraded during five days

Table 1. Proprieties of gatifloxacin molecule.

\begin{tabular}{|c|c|c|c|c|}
\hline Compound & Structure & $\begin{array}{c}\text { Molecular } \\
\text { Weight }\end{array}$ & $\begin{array}{c}\text { Wavelength } \\
\text { of } \\
\text { absorption }\end{array}$ & $\begin{array}{c}\text { Water } \\
\text { Solubility }\end{array}$ \\
\hline Gatifloxacin & absorption & $\begin{array}{c}40-60 \\
\text { maximum at } \\
287.5 \mathrm{~nm}\end{array}$ & $\mathrm{mg} / \mathrm{mL}$ \\
\hline
\end{tabular}

\section{Results and discussion}

Influence of applied current on the oxidative degradation kinetics of gatifloxacin aqueous solution.

The primary factors which influence on EF process are applied current, catalyst concentration, solution $\mathrm{pH}$ and background electrolyte. In different researches, it is mentioned that the optimal $\mathrm{pH}$ value is about $3^{22-25}$ and the more appropriate supporting electrolyte is $\mathrm{Na}_{2} \mathrm{SO}_{4}{ }^{26}$.

In order to study the effect of applied current on the degradation of gatifloxacin, $200 \mathrm{~mL}$ of $0.1 \mathrm{mM}$ gatifloxacin solution with $0.1 \mathrm{mM} \mathrm{Fe}{ }^{2+}$ at $\mathrm{pH}=3$ are used (Fig. 1).

The use of these data cited before determines the optimal applied current where oxidation of gatifloxacin is favored for which the oxidation of Gati.

The evolution of the concentration of gatifloxacin is followed using the high-performance liquid chromatography (HPLC).
Raising the applied current value from 100 to 500 $\mathrm{mA}$ carry on the accelerated oxidation kinetics of Gati. This behavior can be justified by the acceleration of the rate of electrochemical reactions (2) and (3), and thus, there is the production of more $\cdot \mathrm{OH}$ radicals (reaction (1)).

Raising the applied current value from 100 to 500 $\mathrm{mA}$ carry on the accelerated oxidation kinetics of Gati. This behavior can be justified by the acceleration of the rate of electrochemical reactions (2) and (3), and thus, there is the production of more $\cdot \mathrm{OH}$ radicals (reaction (1)).

The complete degradation of Gati was checked at $6,3,2.5$ and $3 \mathrm{~min}$ for the intensities of 100, 300, 400 and $500 \mathrm{~mA}$, respectively. Thus, after $400 \mathrm{~mA}$, the degradation rate of Gati was not significantly varied. Consequently, the optimal value of the applied current is $400 \mathrm{~mA}$. Supplementary increase in this current carried on decreasing oxidative efficiency of Gati by dedicating a long time of electrolysis for the complete degradation of Gati. 


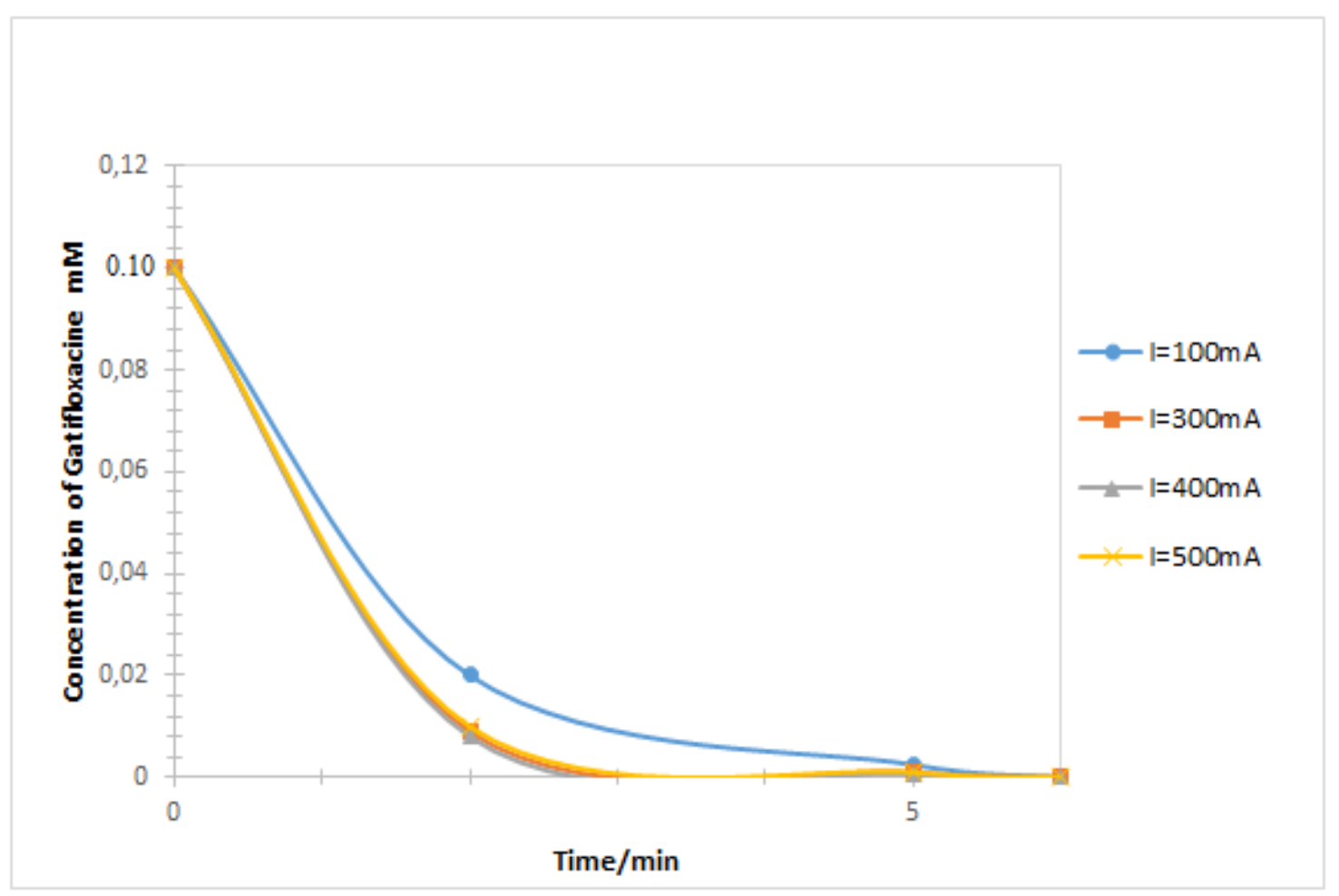

Figure 1. Effect of applied current on degradation of gatifloxacin during the electrolysis at $\mathrm{pH} 3$, $[\mathrm{Gati}]_{0}=0.1$ $\mathrm{mM}, 0.05 \mathrm{M} \mathrm{Na}_{2} \mathrm{SO}_{4}$, with $\left[\mathrm{Fe}^{2+}\right]=0.1 \mathrm{mM}, \mathrm{I}(\mathrm{mA})=100(-\bullet-), 300(-\mathbf{-}), 400\left(-\boldsymbol{\Delta}_{-}\right)$and $500\left(-x_{-}\right)$

Influence of the catalyst $\mathrm{Fe}^{2+}$ on the oxidative degradation kinetics of gatifloxacin in aqueous solution.

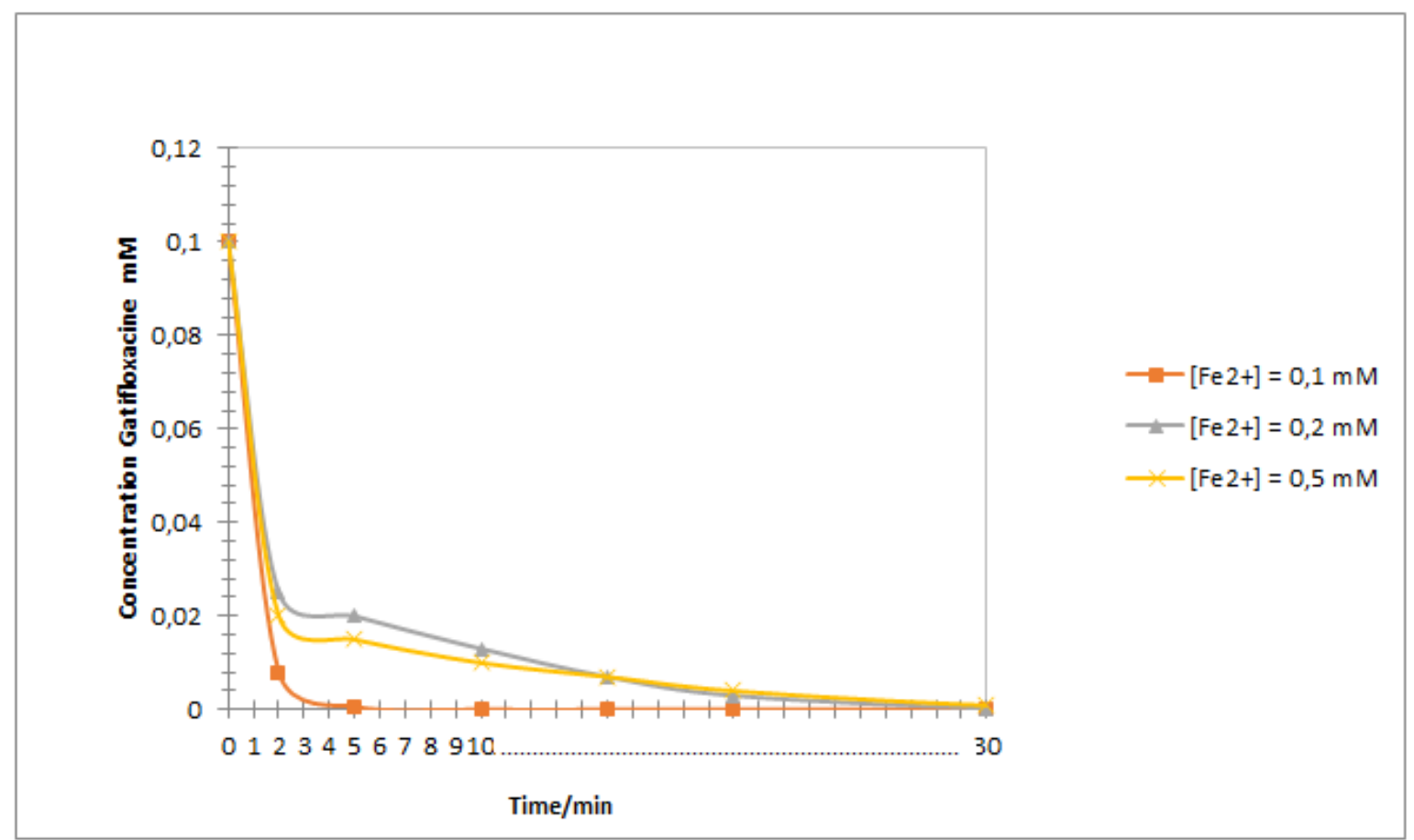

Figure 2. Effect of $\mathrm{Fe}^{2+}$ concentration on Gati concentration decay during the electrolysis at $\mathrm{pH} 3$ in $[\mathrm{Gati}]_{0}=0.1$ $\mathrm{mM}$ and $0.05 \mathrm{M} \mathrm{Na}_{2} \mathrm{SO}_{4}$ solution at $\mathrm{I}=400 \mathrm{~mA}$. $\left[\mathrm{Fe}^{2+}\right](\mathrm{mM})=0.1(-\mathbf{-}-), 0.2\left(-\boldsymbol{\Delta}_{-}\right)$and $0.5\left(-\mathbf{x}_{-}\right)$

Higher applied current could be an origin for the speed-up of following wasting reactions:

$\mathrm{O}_{2}+4 \mathrm{e}^{-}+4 \mathrm{H}^{+} \rightarrow 2 \mathrm{H}_{2} \mathrm{O}$

$$
2 \mathrm{H}_{2} \mathrm{O}+2 \mathrm{e}^{-} \rightarrow \mathrm{H}_{2}+2 \mathrm{OH}^{-}
$$$$
\mathrm{H}_{2} \mathrm{O}_{2} \rightarrow \mathrm{O}_{2}+2 \mathrm{H}^{+}+2 \mathrm{e}^{-}
$$ 
In the objective to show the effect of $\mathrm{Fe}^{2+}$ concentration on oxidation of Gati, many experiments were realized by changing the concentration of the catalyst in the range of $0.1-0.5 \mathrm{mM}$ with $400 \mathrm{~mA}$ as optimal current value as it is shown in Fig. 2. After the value $0.1 \mathrm{mM}$ of the catalyst concentration, there is an inhibition of the degradation of the gatifloxacin solution, which explains the parasitic reaction between the $\mathrm{Fe}^{2+}$ ions and the radical hydroxyls (reaction (7))
The time of the treatment by EF for the complete disappearance of Gati has been changed, so this elimination has been realized at 5,30 and $30 \mathrm{~min}$ for $0.1,0.2$ and $0.5 \mathrm{mM}$ of $\mathrm{Fe}^{2+}$ concentration, respectively.

We conclude that higher concentrations of catalyst reduce the process efficiency because of increase of the rate of its reaction with the hydroxyl radical (reaction (7)) ${ }^{5,27}$ :

$\mathrm{Fe}^{2+}+\cdot \mathrm{OH} \rightarrow \mathrm{Fe}^{3+}+\mathrm{OH}^{-}$

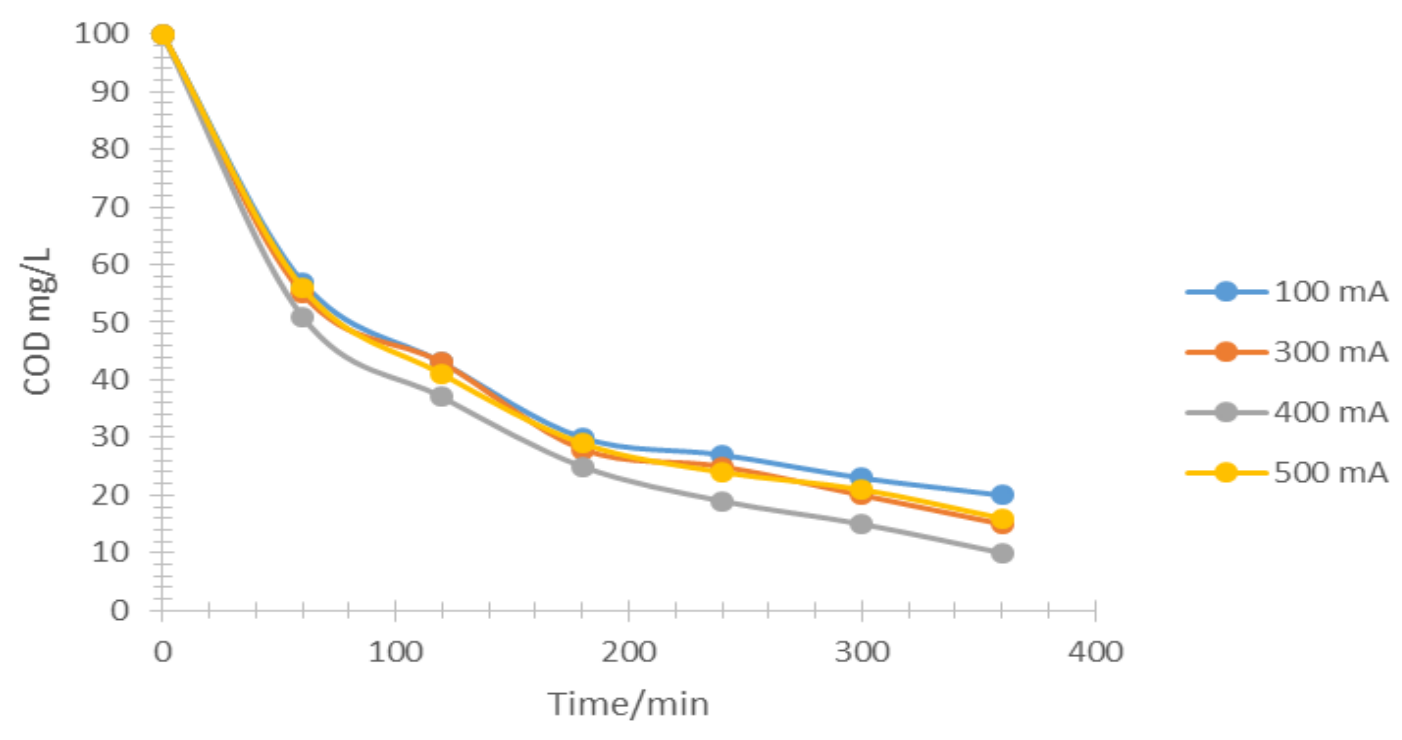

Figure 3. Effect of applied current on gatifloxacin $(0.1 \mathrm{mM})$ mineralization during the electrolysis at $\mathrm{pH} 3$ in $0.05 \mathrm{M} \mathrm{Na}_{2} \mathrm{SO}_{4}$ solution. $\left[\mathrm{Fe}^{2+}\right](\mathrm{mM})=0.1$. I $(\mathrm{mA})=100\left(-^{\bullet}\right), 300\left(-^{\bullet}\right), 400\left(-_{-}^{-}\right)$and $500\left(-_{-}\right)$

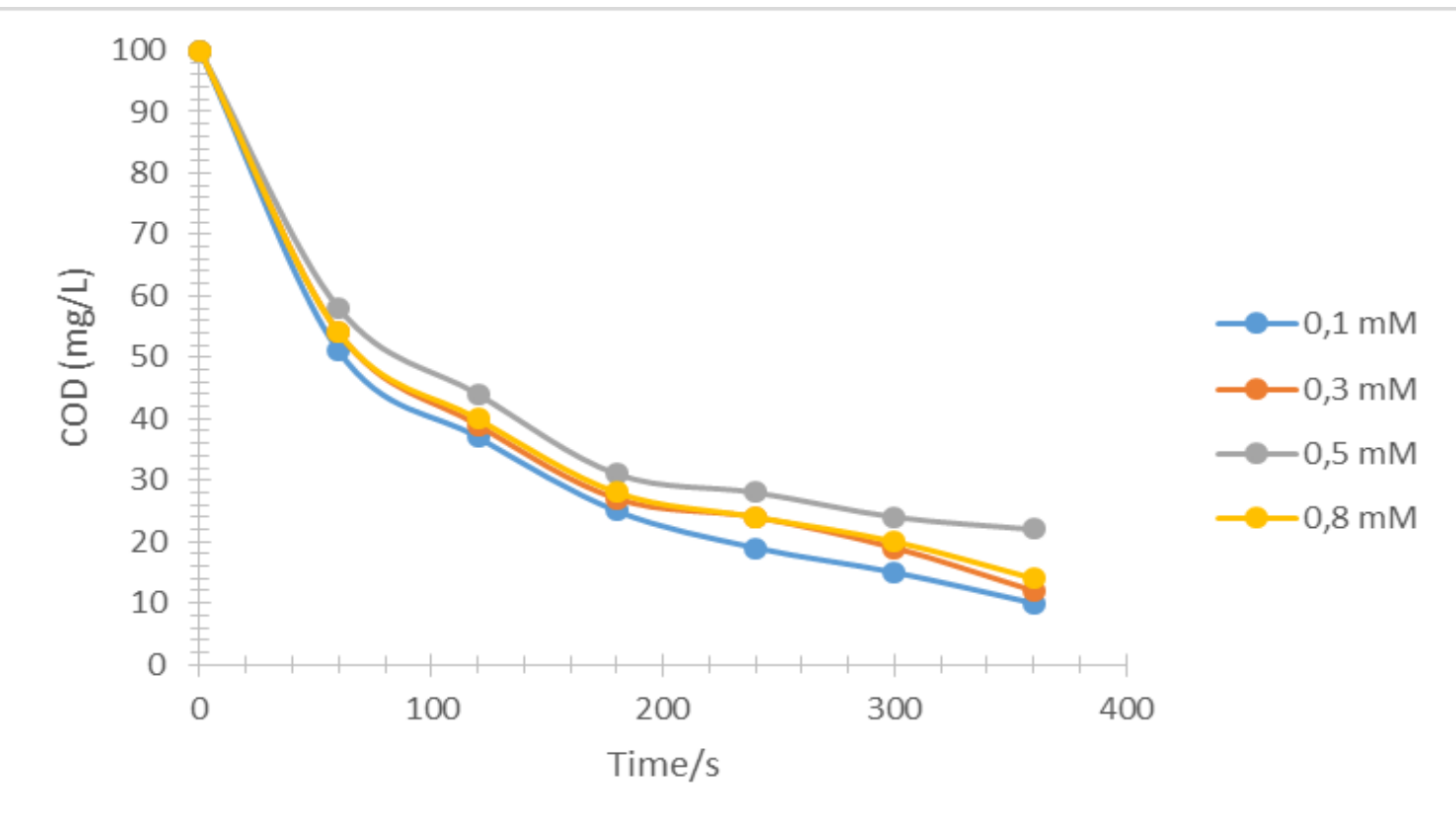

Figure 4. Effect of catalyst concentration on gatifloxacin $(0.1 \mathrm{mM})$ mineralization during electro-Fenton treatment at pH 3 in $0.05 \mathrm{M} \mathrm{Na}_{2} \mathrm{SO}_{4}$ solution. I $(\mathrm{mA})=400 \mathrm{~mA} .\left[\mathrm{Fe}^{2+}\right](\mathrm{mM})=0.1\left(-^{\bullet}\right), 0.3\left(-^{\bullet}\right), 0.5\left(-_{--}\right)$and 
Influence of operating parameters on the mineralization of gatifloxacin in an aqueous medium

Many experiments have been realized with various applied current values with a concentration of $\mathrm{Fe}^{2+}$ about $0.1 \mathrm{mM}$ to study the mineralization of gatifloxacin in water by the electro-Fenton process (Fig. 3).

Indeed, during electrolytic treatment, the COD decreases in a continuous way showing the degradation of gatifloxacin as well as its by-products generated during the electrolysis. At high times of the treatment by EF, COD attained shallow values, indicating the complete mineralization of the polluted molecules. For example, the COD reduces, and we obtained $85 \%$ of it diminution after 6 hours of electrolysis for $300 \mathrm{~mA}$.

According to Figure 3, the COD decay rate raises by raising the applied current value from 100 to 500 $\mathrm{mA}$. After $400 \mathrm{~mA}$, a rise in the applied current did not present any positive effect on the COD decay rate. In consequence, this carried on weak COD values due to the acceleration of wasting reaction (4) that can disturb the production of Fenton's reagent.

Thus, the applied current of $400 \mathrm{~mA}$ may be considered as the optimum for a maximum mineralization rate. So, the mineralization degrees after 6 hours of electrolysis about $80 \%, 85 \%, 90 \%$ and $84 \%$ for $100,300,400 \mathrm{~mA}$ and $500 \mathrm{~mA}$, are respectively obtained.

Many essays have been realized by varying the catalyst concentrations $(0.1$ to $0.8 \mathrm{mM})$ at $400 \mathrm{~mA}$ during electrolysis with EF (Fig. 4).

After the value $0.1 \mathrm{mM}$ of the catalyst concentration, there is an inhibition of the removal rate of the gatifloxacin solution, which explains the parasitic reaction between the $\mathrm{Fe}^{2+}$ ions and the radical hydroxyls (reaction (7)) ${ }^{28}$. Similar results exist in the literature ${ }^{5}$. Thus, the parameter $\mathrm{Fe}^{+}$is very impacting in the electrolysis by $\mathrm{EF}$.

\section{Identification of the reaction intermediates}

The stable by-products formed during the electrolysis are determined using LC/MS-MS analyses. The results correspond to the first $1 \mathrm{~h}(0 \mathrm{~min}$, $15 \mathrm{~min}, 30 \mathrm{~min}$ and $1 \mathrm{~h}$ ) of the treatment by the EF process showed an increasing disappearance of gatifloxacin and formation of some by-products. The concentration of these products goes to maxima and then decrease until full disappearance.

Table 2 represents the identified by-products, while mass spectra of these intermediates are shown in Fig. 5.

Table 2. The intermediates identified by LC/MS-MS during the mineralization of gatifloxacin by EF process.

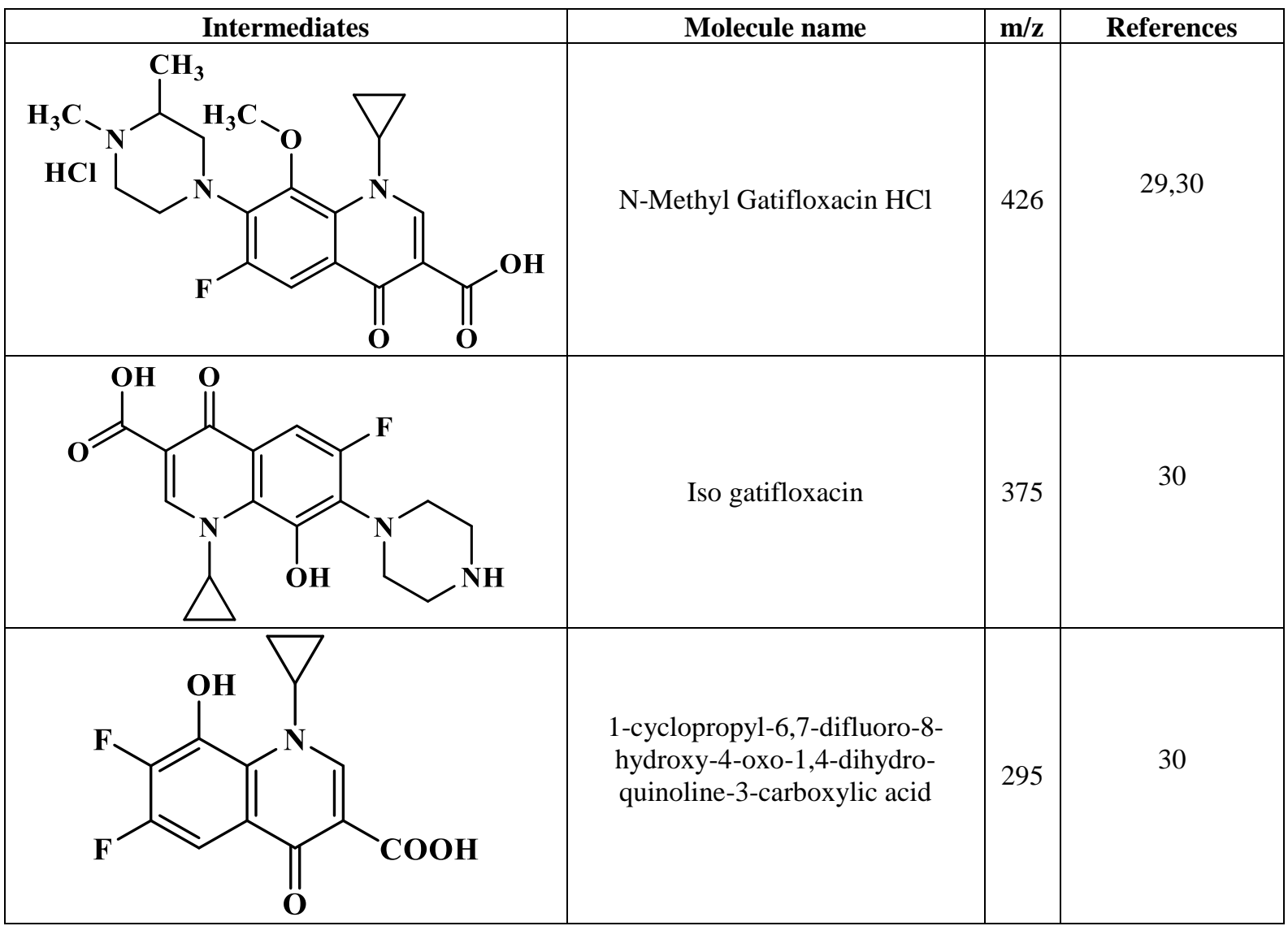



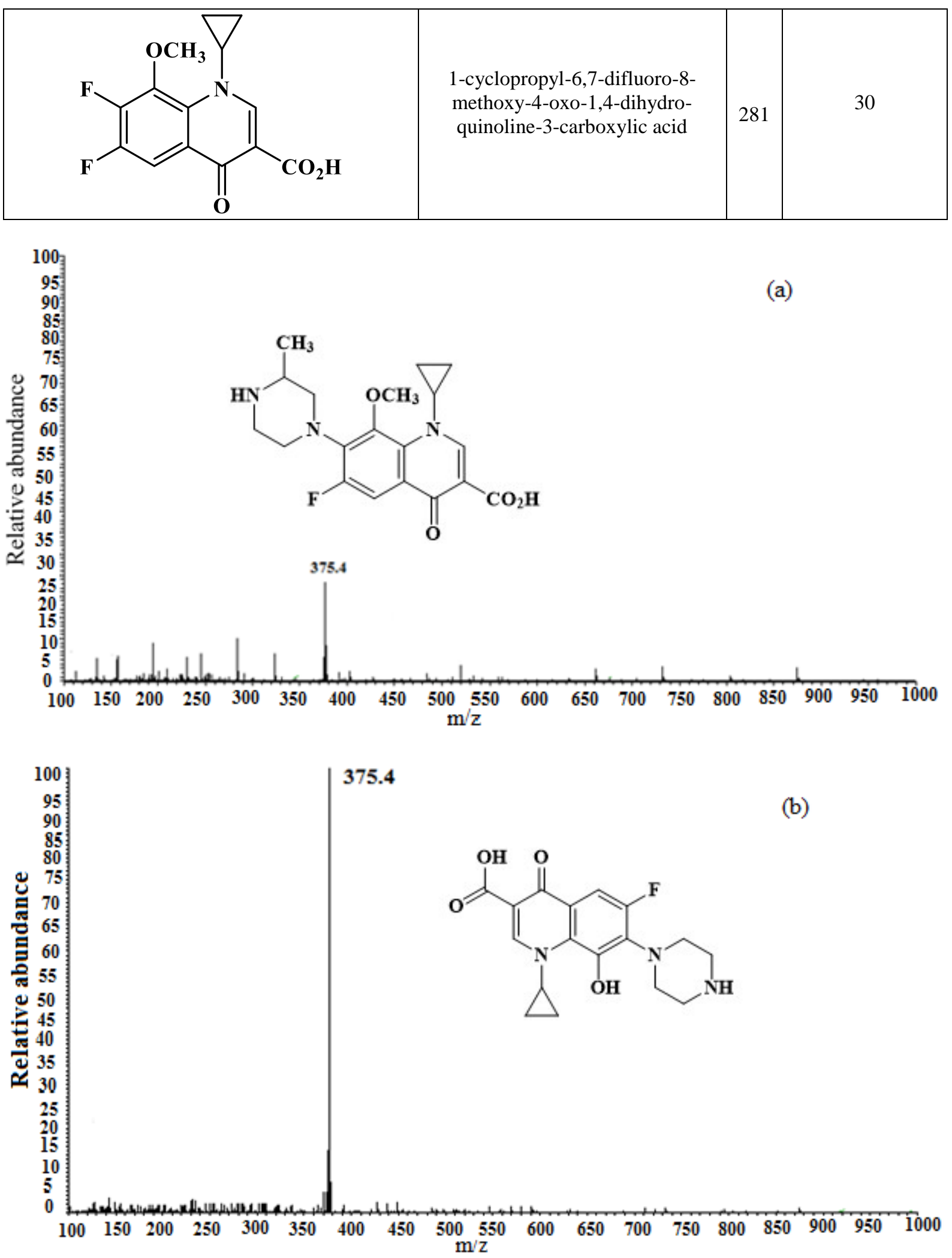

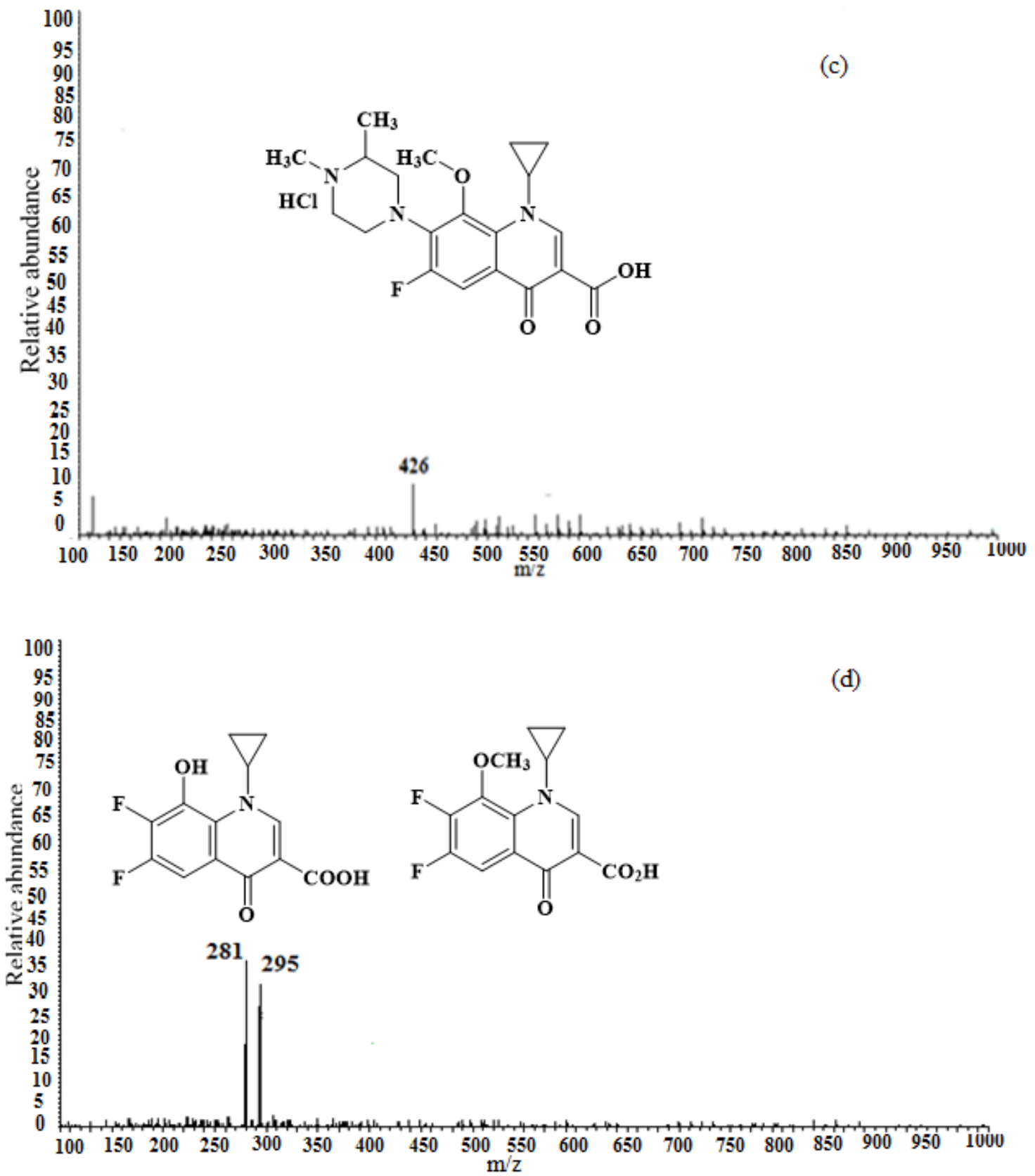

Figures 5. (a, b, c, d) spectra of by-products existing in the aqueous medium during $1 \mathrm{~h}$ of electrolysis of gatifloxacin. $\left[\mathrm{Fe}^{2+}\right]=0.1 \mathrm{mM}, \mathrm{I}=400 \mathrm{~mA},\left[\mathrm{Na}_{2} \mathrm{SO}_{4}\right]=0.05 \mathrm{M}, \mathrm{pH} 3$.

\section{Biodegradability study}

The biodegradation and mineralization of the samples are illustrated in Fig. 6 at an applied current of $400 \mathrm{~mA}$ and with $\mathrm{Fe}^{2+}$ as catalyst $(0.1 \mathrm{mM})$.

The Figure 6 shows that the starting molecule (gatifloxacin) is non-biodegradable with $\mathrm{BOD}_{5} / \mathrm{COD}$ has a value zero. Also, during 100 minutes of electrolysis, the primary intermediates (refractory aromatic molecules) are non-biodegradable since $\mathrm{BOD}_{5} / \mathrm{COD}$ equal at zero. Then, the biodegradability increases and at about $\mathrm{t}=150$ minutes of $\mathrm{EF}$ treatment, the $\mathrm{BOD}_{5} / \mathrm{COD}$ attains the value 1.1 . This shows that the molecules present in the water become biodegradables ${ }^{31}$. Therefore, biological treatment may be started. Then, between 150 and $300 \mathrm{~min}$, the by-products from electrolysis still react with ${ }^{\circ} \mathrm{OH}$, and indeed there is a high biodegradability (it is small aliphatic molecules: short-chain molecules, as it is known in the literature. 


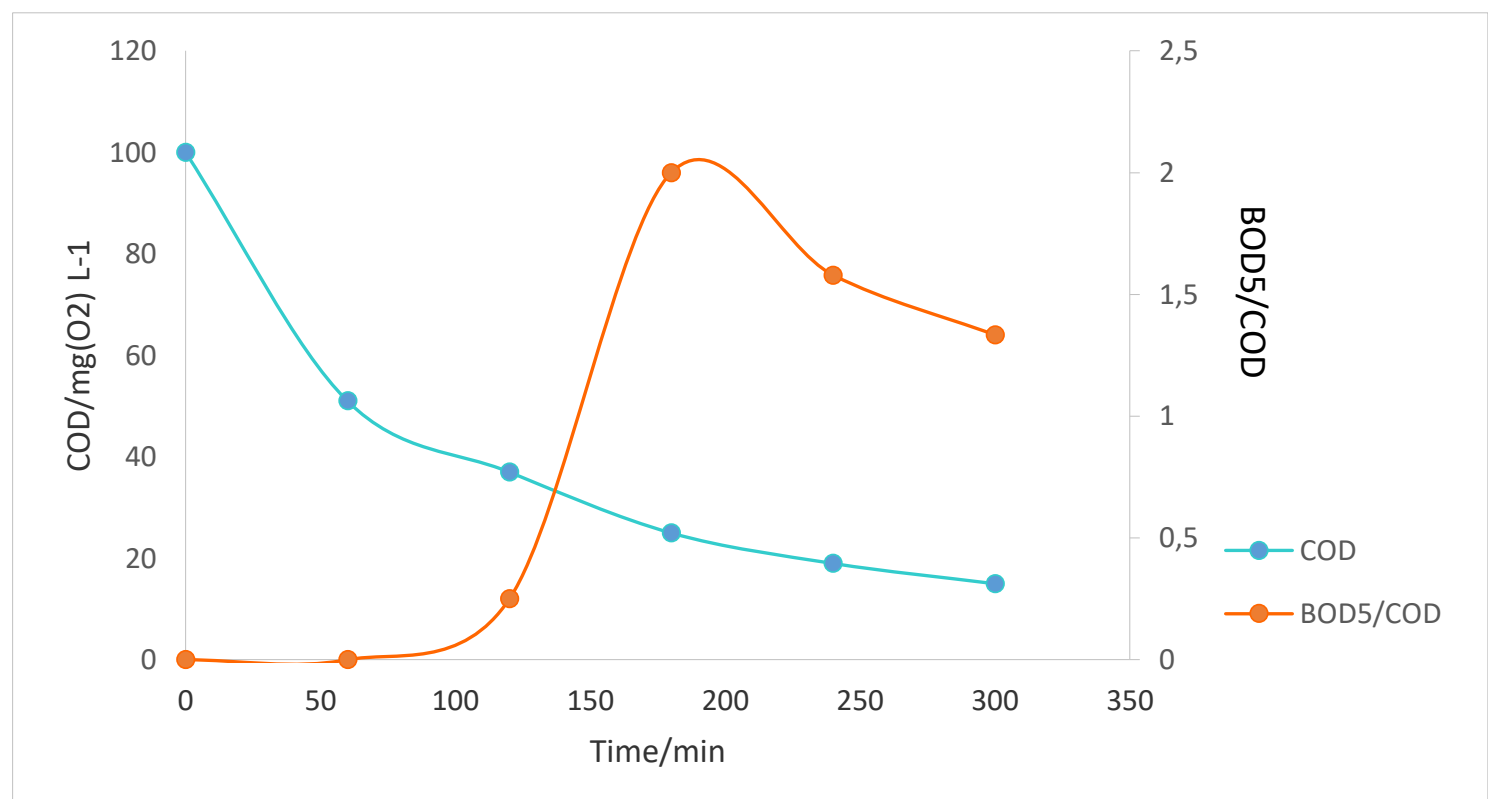

Figure 6. Biodegradability evolution and COD decay during the electrolysis $\left(\mathrm{I}=400 \mathrm{~mA}\right.$ and $\left.\left[\mathrm{Fe}^{2+}\right]=0.1 \mathrm{mM}\right)$.

\section{Comparison between the biodegradability of gatifloxacin and that of gentamicin}

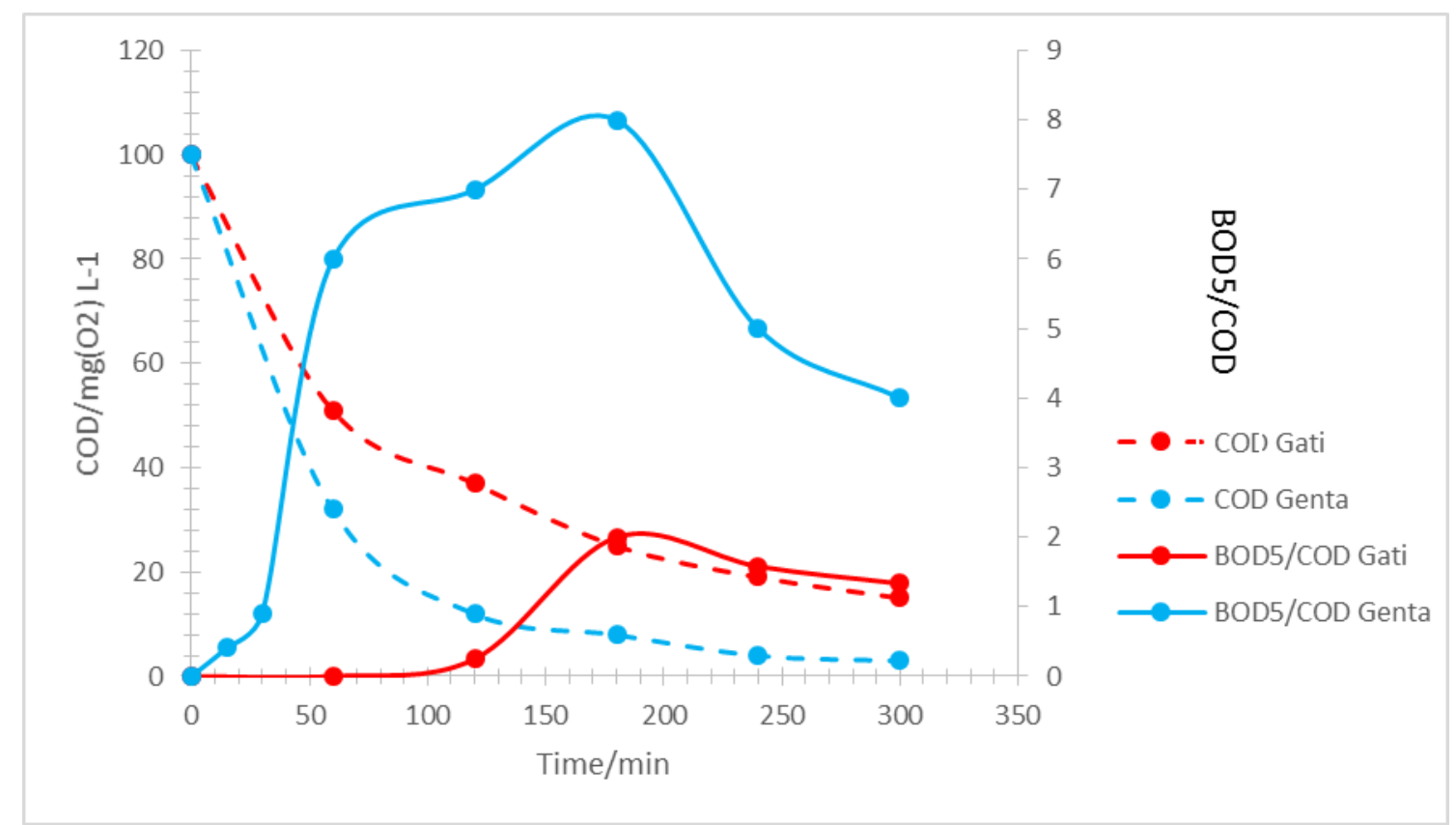

Figure 7. Comparison between the biodegradability of gatifloxacin and the biodegradability of gentamicin. Optimal operating parameters for Gati at $\mathrm{I}=400 \mathrm{~mA}$ and concentration of $\mathrm{Fe}^{2+}$ of $0.1 \mathrm{mM}$ and for Genta at $\mathrm{I}=100 \mathrm{~mA}$ and concentration of $\mathrm{Fe}^{2+}$ of $0.1 \mathrm{mM}$.

First, we have chosen the case of gentamicin for a comparison with the case of gatifloxacin since there is a significant difference concerning the behavior of both antibiotics in terms of biodegradability.

Second, according to the Figure 7 , note that in the case of gentamicin, the solution becomes biodegradable after $30 \mathrm{~min}$ of treatment EF while for gatifloxacin is only biodegradable after $150 \mathrm{~min}$.

For Gati, there is the formation of aromatic molecules (Table 2) between $0 \mathrm{~min}$ and $150 \mathrm{~min}$ of electrolysis which are resistant for the biological treatment with $\mathrm{BOD}_{5} / \mathrm{COD}$ equal to zero and easily degradable by the treatment EF. Also, between 150 min and $6 \mathrm{~h}$ of electrolysis, there is the formation of aliphatic molecules (with short chain) who are easily degradable biologically and resistant at the treatment EF. However, for gentamicin (Table 3), from the beginning (after $30 \mathrm{~min}$ ) the molecules aromatics existing in the solution (Table 3 ) are biodegradables according to the literature ${ }^{32}$. 
Table 3. The intermediates identified by LC/MS-MS during the mineralization of gentamicin by EF process.

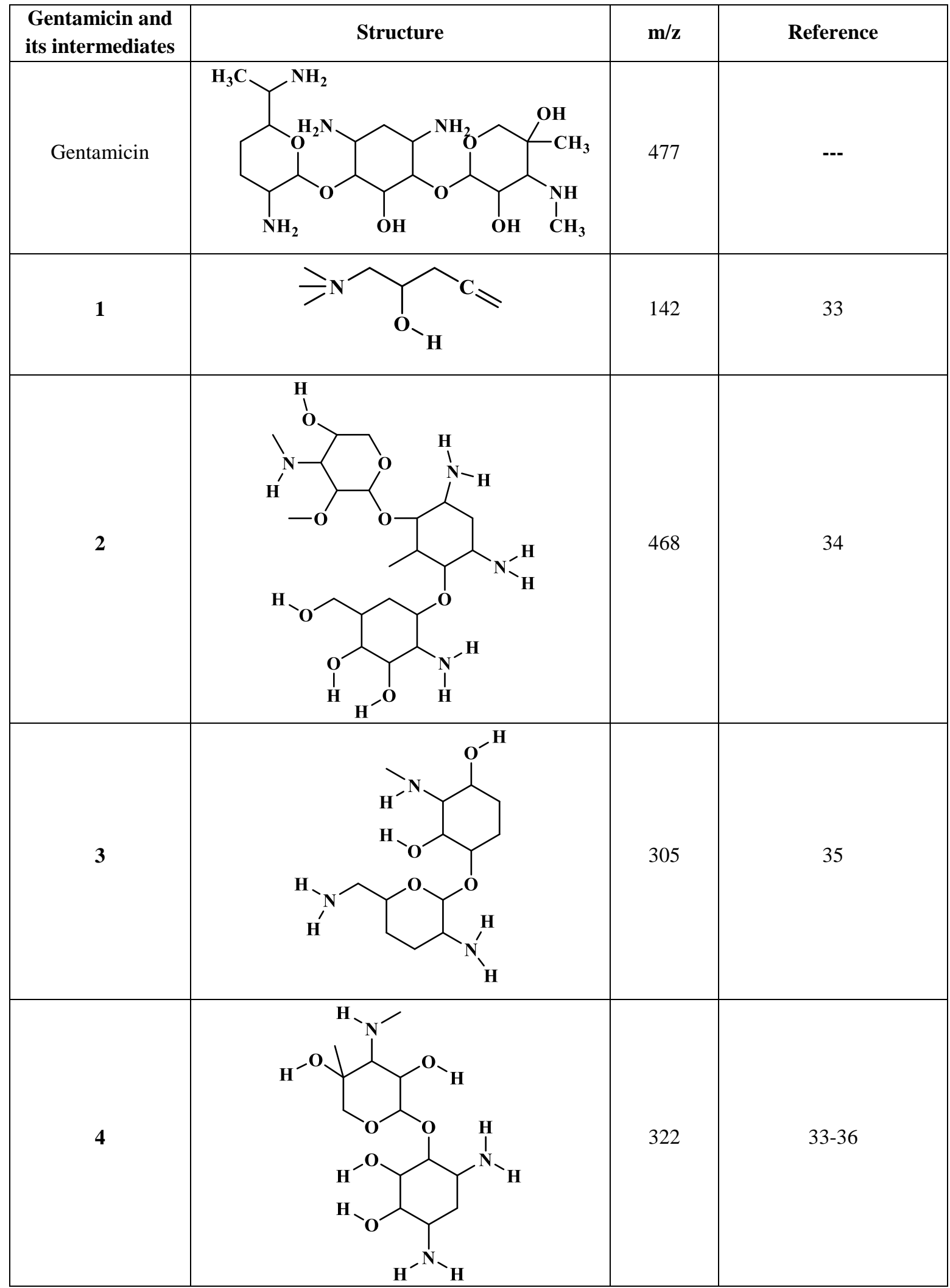




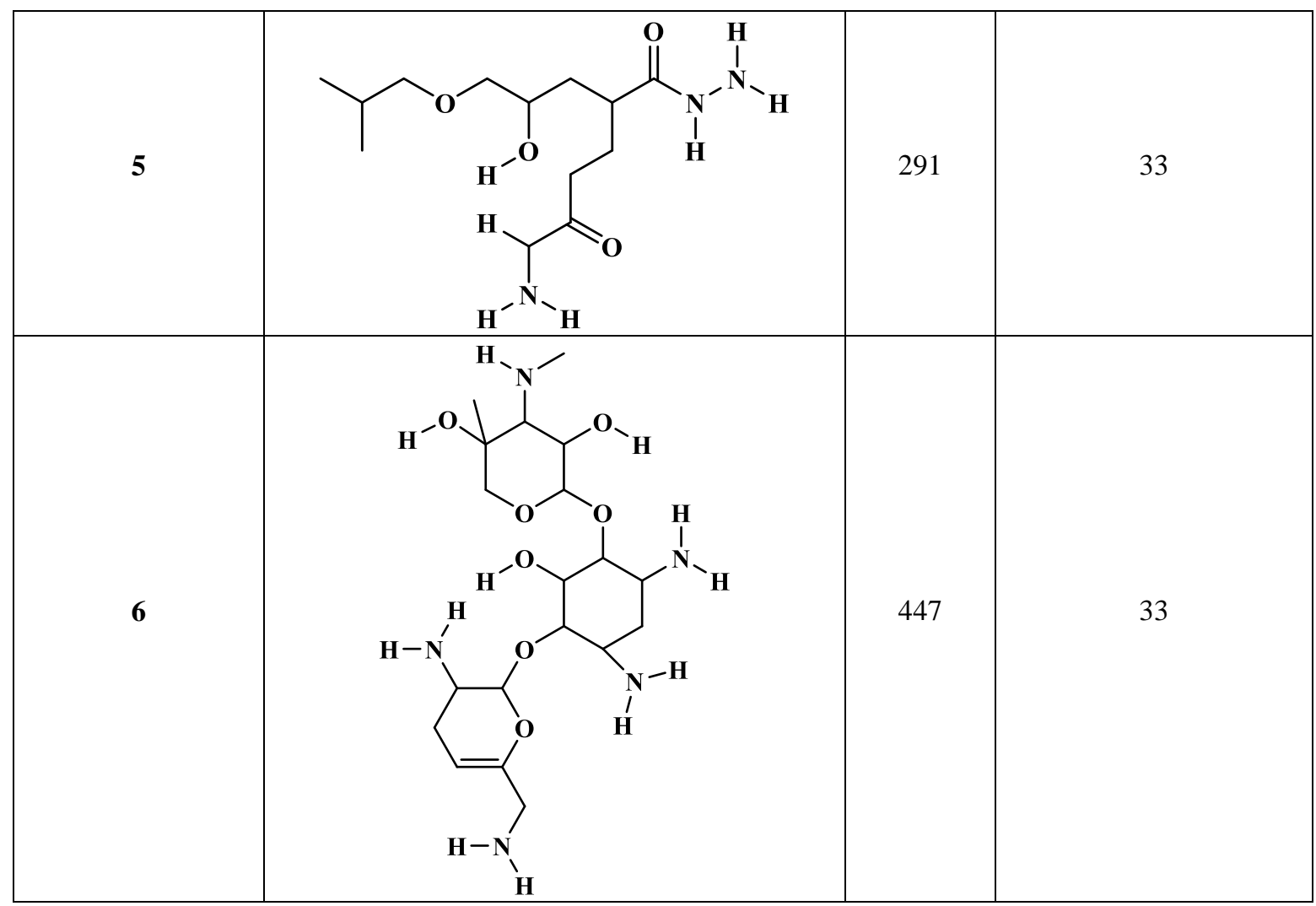

\section{Conclusion}

It has been showed that for a $0.1 \mathrm{mM}$ gatifloxacin concentration, $\mathrm{I}=400 \mathrm{~mA}$ and $\left[\mathrm{Fe}^{2+}\right]=0.1 \mathrm{mM}$ constitute the optimum. Under these operational conditions, gatifloxacin disappears completely after 2 min of electro Fenton treatment, and the COD elimination attains $90 \%$ after 6 hours showing the mineralization of gatifloxacin in an aqueous medium.

The biodegradability study indicated that during 100 minutes of electrolysis, the $\mathrm{BOD}_{5} / \mathrm{COD}$ ratio is equal to zero showing that the solution is nonbiodegradable, thus indicating that gatifloxacin and its sub - aromatic products are biologically resistant. Next, the biodegradability improves and at about $\mathrm{t}=150$ minutes of EF electrolysis, the $\mathrm{BOD}_{5} / \mathrm{COD}$ reaches the value 1.1 , showing that the solution which contains the aliphatics principally, becomes biodegradable. This indicates that electro-Fenton pretreatments can enhance biodegradability by forming other biodegradable by-products that could be easily biodegraded.

So, a coupling between electrolytic treatment with a biological one could be seen as a perspective for determining the time in order to pass since the electrolysis to the biological process so that to minimize the cost of the global treatment. This leads to effective treatment of waters polluted with gatifloxacin at a lower cost.

\section{References}

1- a) F. Weber, T. Beek, A. Bergmann, A. Carius, G. Grüttner, S. Hickmann, Les Produits Pharmaceutiques dans l'Environnement Perspective à l'Echelle Mondiale. Présence, Effets, et Action Concertée Potentielle au Titre de la SAICM, 2014.

b) D. Destrieux, F. Laurent, H. Budzinski, J. Pedelucq, P. Vervier, M. Gerino, Drug residues in urban water: A database for ecotoxicological risk management, Science of the Total Environment, 2017, 609, 927-941.

2- U. Von Gunten, Ozonation of Drinking Water: Part I, Oxidation Kinetics and Product.

Formation. Water Res., 2003, 37, 1443-1467.

3- A. Fujishima, X. Zhang, D. A. Tryk, Photocatalysis and Related Surface Phenomena. Surf. Science Rep, 2008, 63, 515-582.

4- A. Y. C. Tong, B. Braund, D. S. Warren, B. M. Peake, TiO2-assisted Photodegradation of Pharmaceuticals, a review. Cent. Eur. J. Chem., 2012, 10, 989-1027.

5- M. A. Oturan, An Ecologically Effective Water Treatment Technique Using Electrochemically Generated Hydroxyl Radicals for in Situ Destruction of Organic Pollutants. Application to Herbicide 2,4-D. Appl Electrochem, 2000, $30,477-48$ 
6- M. Sh. Yahya, N. Oturan, K. El Kacemi, M. El Karbane, C. T. Aravindakumar, M. A. Oturan, Oxidative Degradation Study on Antimicrobial Agent Ciprofloxacin by Electro-Fenton Process: Kinetics and Oxidation Products. Chemosphere, 2014, 117, 447-454.

7- M. Sh. Yahya, M. El Karbane, N. Oturan, K. El Kacemi, M. A. Oturan, Mineralization of the Antibiotic Levofloxacin in Aqueous Medium by Electro- Fenton Process: Kinetics and Intermediate Products Analysis. Environ Technol, 2016, vol. 37, NO. 10, 1276-1287.

8- M. Sh. Yahya, N. Beqqal, A. Guessous, M. R. Arhoutane, K. El Kacemi, Degradation and Mineralization of Moxifloxacin Antibiotic in Aqueous Medium by Electro-Fenton Process: Kinetic Assessment and Oxidation Products. Cogent Chemistry, 2017, 3, 1290021.

9- M. A. Oturan, I. Sirès, N. Oturan, S. Pérocheau, J. L. Laborde, Sonoelectro Fenton Process: A Novel Hybrid Technique for the Destruction of Organic Pollutants in Water. J. Electroanal. Chem., 2008, 624, 329-332.

10- L. Ge, C. Halsall, C. Chen, P. Zhang, Q. Dong, Z. Yao, Exploring the Aquatic Photodegradation of Two Ionisable Fluoroquinolone Antibiotics - Gatifloxacin and Balofloxacin: Degradation Kinetics, Photo byproducts and Risk to the Aquatic Environment, Sci. Total Environ., 2018, 633, 1192-1197

11- G. Linke, C. JingWen*, Z. SiYu, C. XiYun, W. Zhuang, W. ChunLing, Photodegradation of Fluoroquinolone Antibiotic Gatifloxacin in Aqueous Solutions, Environ. Chem., 2010, Vol.55 No.15: 1495-1500

12- A. Wang, J. H. Qu, J. Ru, Mineralization of an Azo Dye Acid Red 14 by Electro-Fenton`s Reagent Using an Activated Carbon Fiber Cathode. Dyes Pigments, 2005, 6, 227-233.

13- I. Sirés, N. Oturan, M. A. Oturan, R. M. Rodríguez, J. A. Garrido, E. Brillas, ElectroFenton Degradation of Antimicrobials Triclosan and Triclocarban. Electrochim. Acta, 2007, 52, 5493 - 5503.

14- E. Isarain-Chávez, C. Arias, P. L. Cabot, F. Centellas, R. M. Rodríguez, J. A. Garrido, E. Brillas, Mineralization of the Drug B-blocker Atenolol by Electro-Fenton and PhotoelectroFenton Using an Air- diffusion Cathode for $\mathrm{H} 2 \mathrm{O} 2$ Electrogeneration Combined with a Carbon-felt Cathode for $\mathrm{Fe} 2+$ Regeneration. Application Catalytic B-Environnement, 2010, 96, 361-369.

15- C. M. Rui, A. F. Rossi, R. M. Quinta-Ferreira, Fenton's Oxidation Process for Phenolic Wastewater Remediation and Biodegradability Enhancement, J. Hazard. Mater., 2010, 180, 716-721.

16- S. Sonia, A. M. Polo, M. Tobajas, J. J. Rodriguez., A. F. Mohedano, Degradation of Chlorophenoxy Herbicides by Coupled Fenton and Biological Oxidation. Chemosphere, 2013, 93, 115-122.

17- L. Li-An, M. Ying-Shih, M. Kumar, L. JihGaw, Photo-Fenton Pretreatment of Carbofuran - Analyses via Experimental Design, Detoxification and Biodegradability Enhancement. Sep. Purif. Technol., 2011, 81, 325-331.

18- M. Dorsaf, F. Fourcade, I. Soutrel, D. Hauchard, N. Bellakhal, A. Amrane, Relevance of a Combined Process Coupling Electro-Fenton and Biological Treatment for the Remediation of Sulfamethazine Solution Application to an Industrial Pharmaceutical Effluent. C. R. Chimie, 2015, 18, 39-44.

19- O. Hugo, T. Cocerva, N. Oturan, D. Buisson, M. A. Oturan, A Sustainable Integrated Process for Removal of Organic Pollutants from Water: Application to Mineralization of Metoprolol. J. Hazard. Mater., 2016, 319, 13-23.

20- A. Cyrine, F. Fourcade, I. Soutrel, F. Geneste, D. Floner, N. Bellakhal, A. Amrane, Degradation of Enoxacin Antibiotic by the Electro-Fenton Process: Optimization, Biodegradability Improvement and Degradation Mechanism. J. Environ. Manage., 2016, 165, 96-105.

21- D. Mantzavinos, E. Psillakis, Enhancement of Biodegradability of Industrial Wastewaters by Chemical Oxidation Pre-treatment. J. Chemistry. Technology. Biotechnology, 2004, 79, 431- 454.

22- J. J. Pignatello, Y. Sun., Complete Oxidation of Metolachlor and Methyl Parathion in Water by the Photoassisted Fenton Reaction. Water Res., 1995, 29, 837-1844.

23- B. Boye, M. M. Dieng, E. Brillas, Degradation of Herbicide 4-Chlorophenoxyacetic Acid by Advanced Electrochemical Oxidation Methods. Environ. Sci. Technol., 2002, 36, 3030-3035.

24- N. Oturan, M. Panizza, M. A. Oturan, Cold Incineration of Chlorophenols in Aqueous Solution by Electro- Fenton Process. Effect of Number and Position of Chlorine Atoms on the Degradation Kinetics. J. Phys. Chem., 2009, A 113, 10988-10993.

25- A. Dirany, Études cinétique et mécanistique d'oxydation/minéralisation des antibiotiques sulfaméthoxazole (SMX), amoxicilline (AMX) et sulfachloropyridazine (SPC) en milieux aqueux par procédés électrochimiques d'oxydation avancée. Mesure et suivi d'évolution de la toxicité lors du traitement, 2010.

26- M. Sh. Yahya, N. Oturan, K. El Kacemi, M. El Karbane, C. T. Aravindakumar, M. A. Oturan, Oxidative Degradation Study on Antimicrobial Agent Ciprofloxacin by Electro-Fenton Process: Kinetics and Oxidation Products. Chemosphere, 2014, 117, 447-454.

27- E. Brillas, I. Sirés, M. A. Oturan, ElectroFenton Process and Related Electrochemical 
Technologies Based on Fenton's Reaction Chemistry. Chem. Rev. 2009, 109, 6570-6631.

28- H. Zazou, N. Oturan, H. Zhang, M. Hamdani, M. A. Oturan, Comparative study of electrochemical oxidation of herbicide 2,4,5-T: Kinetics, parametric optimization and mineralization pathway. Sustainable Environ. Res., 2017, 27, 15-23.

29- www.pharmaffiliates.com/impurities/2023/gatif loxacin

30- www.bocsci.com/im-gatifloxacin-andimpurities-list-180.html

31- N. Oturan, M. Panizza, M. A. Oturan, Cold Incineration of Chlorophenols in Aqueous Solution by Electro- Fenton Process. Effect of Number and Position of Chlorine Atoms on the Degradation Kinetics. J. Phys. Chem., 2009, A 113, 10988-10993.

32- J. Kondo, M. Koganei, T. Kasahara, Crystal Structure and Specific Binding Mode of
Sisomicin to the Bacterial Ribosomal Decoding Site, ACS Med. Chem. Lett., 2012, 3, 741-744.

33- W. Ulrich, A. Sievers-Engler,

M. Lämmerhofer, Preparation of Fluorescent Labeled Gentamicin as Biological Tracer and Its Characterization by Liquid Chromatography and High-Resolution Mass Spectrometry. J Pharm Biomed Anal., 2016, 121, 307-315.

34- R. Grahek, L. Zupančič-Kralj, Identification of Gentamicin Impurities by Liquid Chromatography-Tandem Mass Spectrometry, J. Pharm. Biomed. Anal., 2009, 1037-1043.

35- J. Berdy, J. Kadar Pauncz, Z. Mehesfalvi Vajna, G. Horvath, J. Gyimesi, I. Koczka, Metabolites of Gentamicin-producing Micromonospora Species 1. Isolation and Identification of Metabolites, J. Antibiot., 1977, VOL. XXX NO. 11.

36- European Pharmacopoeia 8.0. 